\title{
Study on the Level of Talent Attractiveness of the Yangtze River Delta Urban Agglomerations Using Bayesian Quantile Regression Method
}

\author{
Yu Zhang1, Haomin Zhang1,2, Lingfang Wei ${ }^{1}$ \\ ${ }^{1}$ School of Science, Guilin University of Technology, Guilin, China \\ ${ }^{2}$ Guangxi Colleges and Universities Key Laboratory of Applied Statistics, Guilin University of Technology, Guilin, China \\ Email: zhanghm@glut.edu.cn
}

How to cite this paper: Zhang, Y., Zhang, H. M., \& Wei, L. F. (2021). Study on the Level of Talent Attractiveness of the Yangtze River Delta Urban Agglomerations Using Bayesian Quantile Regression Method. Theoretical Economics Letters, 11, 1140-1156.

https://doi.org/10.4236/tel.2021.116072

Received: October 9, 2021

Accepted: December 6, 2021

Published: December 9, 2021

Copyright $\odot 2021$ by author(s) and Scientific Research Publishing Inc. This work is licensed under the Creative Commons Attribution International License (CC BY 4.0).

http://creativecommons.org/licenses/by/4.0/

\begin{abstract}
Innovation is the first driving force to lead development, and the carrier of innovation drive is talent, and talent has been an important strategic resource to lead social development in the $21^{\text {st }}$ century. And different levels of cities should focus on the strategy of attracting talents. In this paper, based on the index data of the Yangtze River Delta Urban Agglomerations in 2019, we construct the evaluation talent attractiveness level score and use it to build a Bayesian quantile regression model to map the focus that cities of different levels should focus on talent attraction policies. The results show that the marginal gain of talent attraction is different for different level cities in different dimensions. By quantifying the level of talent attractiveness of different cities through the objective assignment method, we find the differences in the spatial distribution of talent attractiveness of different cities in the Yangtze River Delta region and provide theoretical guidance for the integration of the Yangtze River Delta. At the same time, by exploring the differences in the talent attractiveness of cities of different levels that should be focused on, we find the general rules and provide reference and guidance for other cities.
\end{abstract}

\section{Keywords}

Talent Attraction, Evaluation Index, Yangtze River Delta Urban Agglomerations, Quantile Regression

\section{Introduction}

The $21^{\text {st }}$ century is the era of the knowledge economy, the economic form has changed to knowledge-based and information-based. Modern theoretical re- 
search has also begun to recognize the importance of human capital to urban development. Lucas \& Rossi-Hansberg (2002) have shown that the concentration of human capital drives economic growth by increasing local productivity. The development of cities cannot be separated from the concentration of industries and human capital, and the concentration of talents undoubtedly greatly improves the development efficiency of cities. A country or a city with sufficient talent reserves will have a long momentum of economic development, so the research on talent attraction becomes especially important. In the previous research on talent attraction in cities, due to the data acquisition and the different development status of each city as well as the natural environment and other factors, most of the research objects choose a single big city, while a city needs to effectively develop policies to attract talents, most of them need to find their own positioning according to their actual situation, and the policies introduced should be focused according to their own situation to ensure their own competitive advantage in talent attraction to a greater extent, to ensure their competitive advantage in talent attraction. Therefore, the study of talent attraction in cities with different levels of development is a worthwhile problem to investigate the direction of talent attraction policies in cities with different levels of development and to provide a reference for cities whose policies are affected by the lack of data guidance, and the quantile regression method can be a good solution to this problem, by selecting suitable cities, the quantile regression method can portray to some extent the level of talent attraction in cities with different levels of development. As one of the six major city clusters in the world, the Yangtze River Delta city cluster is not geographically heterogeneous and contains 5 first-tier cities, 9 second-tier cities, 9 third-tier cities, 3 fourth-tier cities, and 1 fifth-tier city, so this paper selects the Yangtze River Delta city cluster as the object of investigation to explore Therefore, this paper selects the Yangtze River Delta city cluster as the object of investigation to explore the direction that cities at different levels of development should focus on to improve the level of talent attraction.

\section{Literature View}

\subsection{The Importance of Talent and the Factors that Affect It}

The early academic research on talent is mainly about talent mobility, the traditional talent mobility models include (March \& Simon, 1958) decision participation talent mobility model and (Mobley, 1982) intrinsic mobility relationship analysis model, etc., while the research on talent mobility gradually expands to talent attraction, exploring the impact of economic and social environment on talent clustering. Porter (1998) pointed out the influence of industrial clusters on talent attraction through a comprehensive and systematic analysis of talent concentration, Audretsch \& Feldman (2004) pointed out that if a country or a region has well-developed basic industries, it must have strong competitiveness in 
talent attraction. Palivos \& Wang (2008) argues that factors that increase the attractiveness of talent include not only the internal and external large-scale market economy, local government incentives, but also salary levels, public resource availability, and the effects of knowledge outflow and spillover. Qian (2010) examined two types of talent: human capital in terms of educational attainment and innovation class in terms of occupational skills, in terms of the relationship between the geographical distribution of talent in China and its innovation, entrepreneurship and regional economic performance. Correlation and multivariate analyses found that universities are an important factor influencing the distribution of talent, and that wage levels, service facilities, and openness also contributes to attracting talent, but to varying degrees. Weng \& McElroy (2010) used one-way ANOVA, hierarchical regression and structural equation modeling to analyze the data. The results found that there were significant differences in the regional attractiveness of the four industry clusters that factors in the macro HR environment directly influenced talent growth and regional attractiveness, and that talent growth partially moderated the relationship between the three levels of the HR environment. It explains why talents are more willing to gravitate toward industry clusters and how the HR environment affects the flow of talents.

\subsection{Research on Individual Cities}

Gao (2012) constructed an evaluation index system for talent attraction in Shanghai from three perspectives: social and cultural atmosphere, institutional environment and living environment. It provides a theoretical basis for the adjustment of talent policy and the shift of focus in Shanghai in the $12^{\text {th }}$ Five-Year Plan period. Liu et al. (2015) and others take Shenzhen as an example to explore the factors influencing the attractiveness of financial talents in Shenzhen, which is of reference. Using the research method of rooting theory, the results of the study show that the city's financial industry environment, cultural atmosphere, living environment, and talent policy have a significant impact on the attractiveness of financial talents in Shenzhen, and the financial industry environment is the fundamental influencing factor of the attractiveness of financial talents in the city. Finally, several suggestions are proposed to enhance the attractiveness of Shenzhen to financial talents.

\subsection{Research on Different Cities}

Song \& Chen (2006) used principal component analysis to quantify the talent attractiveness of each province and region in mainland China in 2003, and found that there were significant differences in talent attractiveness between provinces and regions in China, with five provinces and regions with local maximum, three provinces and regions with local minimum, and eight provinces and regions with local minimum. There are 5 local maximum, 3 local minimum, and 8 local low provinces. Li \& Li (2011) established a talent gathering carrier system 
consisting of main carrier, service carrier and guarantee carrier, summarized the factors influencing talent attractiveness, established the interaction model between talent gathering carrier and talent attractiveness with the help of system dynamics, and made a simulation analysis in the northwest Liaoning region, and proposed measures to increase talent attractiveness in northwest Liaoning region from the perspective of building talent gathering carrier. Measures to increase the attractiveness of talents in the northwest Liaoning region were proposed from the perspective of building talent gathering carriers. Zhang (2012) evaluated and analyzed the differences of talent attractiveness of industrial clusters in Henan Province based on the index system of talent attractiveness of industrial cluster environment by using principal component analysis. Lin et al. (2015) used factor analysis to test the attractiveness of talent in cities along the Wuhan-Guangzhou high-speed railroad line based on the idea of "with and without comparison". The results confirmed that the talent attractiveness of cities in the case of "with" high-speed railroad was significantly higher than that in the case of "without" high-speed railroad, and Wuhan was the city that benefited most from high-speed railway among the three types of cities, followed by Zhuzhou and Guangzhou. Zhang et al. (2017) comprehensively analyzed the main influencing factors of talent attractiveness in first-tier cities, constructed a four-dimensional overall analysis framework, proposed the random forest method for outlier measurement and feature variable selection, designed a logistic regression model of talent attractiveness influencing factors in first-tier cities, and conducted in-depth quantitative analysis of the influencing mode and degree of influence. The results of the study show that among the 17 variables selected for analysis, 9 factors have significant effects. The results of the study provide new analytical methods and practical guidance for first-tier cities in China to explore the influencing factors of talent attractiveness and to further attract talent by taking advantage of regional comparative advantages. Zeng \& Li (2019) conducted a study on the factors influencing the attractiveness of rural talents by conducting a talent questionnaire survey in the western region of $\mathrm{Yu}$, using logistic regression analysis. It was found that for each decrease of one level in the evaluation (satisfaction) of talent on infrastructure, ecological environment, career development, spouse employment, and transportation status factors, the incidence ratio of talent willing to develop in the countryside would decrease by $27.3 \%, 39.8 \%, 28.2 \%, 17.6 \%$, and $28.5 \%$, respectively, indicating that infrastructure, ecological environment, career development, spouse employment, and transportation status have a significant positive relationship with the attractiveness of rural talent. There is a significant positive correlation between infrastructure, ecological environment, career development, spouse employment, transportation and rural talent attractiveness; for each decrease of 1 level in the evaluation (satisfaction) of security environment and recreation factors, the incidence of talent willing to go to rural employment and development will increase by $32.4 \%$ and $15.3 \%$, respectively, which proves that there is a significant negative correlation between security en- 
vironment and recreation factors and rural talent attractiveness; the correlation between preferential policies and rural talent attractiveness variables, at a significant level of 0.1 The correlation between preferential policies and the attractiveness of rural talents did not pass the hypothesis test at 0.1 level of significance, indicating that preferential policies of governments at all levels did not become an important factor to attract talents. The countryside should take measures to make the hardware hard, the environment beautiful, the space wide and the policy flexible to realize the talent revitalization. Ye \& Chen (2019) based on the theory of comfort, constructed a comprehensive attractiveness evaluation index system of cities for scientific and technological innovation talents consisting of 5 primary indicators and 49 secondary indicators in terms of natural ecological environment, economic development level, social living environment, public service level, and scientific and educational innovation environment, and applied entropy value method and cluster analysis method to evaluate the comprehensive attractiveness of 33 major cities in China. The results of the study show that the attractiveness of 33 major cities in China was evaluated and compared. The results of the study show that the comprehensive attractiveness of cities in North, Guangzhou and Shenzhen is significantly higher than that of cities in central and western China, but the scores of each city in different dimensions differ greatly and have different combinations of advantages. Each city should take into account its own characteristics and location conditions, and introduce targeted policies to attract scientific and technological innovation talents. Lin et al. (2020) constructed a multi-level analysis model of the factors influencing the locational preferences of talent mobility from the perspective of urban comfort based on the progress of domestic and foreign research, and used the methods of biographical analysis, multi-indicator analysis and multiple regression to investigate the spatial preferences of the mobility of young scholars introduced by the Young Thousand Talent Program in China and the relationship with urban comfort. Xu et al. (2019) reveal the main points of science and technology policy development in the Yangtze River Delta region of China by analyzing the structure of the policy social network, and the results show that the structure of the science and technology policy system in Shanghai, Jiangsu, Zhejiang and Anhui is relatively consistent, while the development paths are different, and there is a serious homogenization of industrial policy content in the four provinces

Most of the existing literature explores the importance of different indicators based on individual cities and regions of talent attractiveness or explores the comparison of attractiveness levels of different urban areas for spatial comparison, lacking the analysis of the differences between different cities in different dimensions, especially the differences between cities at different levels of development. In terms of assignment methods, also usually only one method is selected, and the comparison of results between different methods is lacking. 


\section{Data Source and Methods}

\subsection{Sample Selection and Data Sources}

This paper takes the Yangtze River Delta Urban Agglomerations as the sample and selects the relevant data in 2019 as the original data, which are obtained from the China City Statistical Yearbook, Anhui Provincial Statistical Yearbook, Jiangsu Provincial Statistical Yearbook and Zhejiang Provincial Statistical Yearbook.

\subsection{Variable Selection and Description}

To measure the attractiveness of a city's talent, we need to take a comprehensive consideration from the perspective of what the talent needs. Through the summary of previous literature, in this paper, the talent needs to consider the natural ecological environment, the level of economic development, the level of public services, the scientific and technological living environment and the scientific and technological innovation environment of the city when choosing a city to settle, and start to design indicators and build an evaluation system, as shown in Table 1.

Table 1. City talent attractiveness evaluation index system.

\begin{tabular}{|c|c|c|c|}
\hline $\begin{array}{l}\text { Target } \\
\text { layer }\end{array}$ & Factor layer & Indicator layer & Properties \\
\hline \multirow{18}{*}{$\begin{array}{l}\text { Talent } \\
\text { attraction }\end{array}$} & \multirow[t]{5}{*}{ Natural Ecology (nature) } & Total water resources (million cubic meters) & Positive \\
\hline & & Greening coverage of built-up areas (\%) & Positive \\
\hline & & $\begin{array}{l}\text { Proportion of air quality meeting and better than secondary standards } \\
\text { (\%) }\end{array}$ & Positive \\
\hline & & Average wage of employees (yuan) & Positive \\
\hline & & Total import and export of goods (million yuan) & Positive \\
\hline & \multirow[t]{4}{*}{ Public Service Level (pub) } & Gross regional product per capita (yuan) & Positive \\
\hline & & $\begin{array}{l}\text { The proportion of urban workers' basic pension insurance participants } \\
\text { to the number of household registration population }\end{array}$ & Positive \\
\hline & & Number of hospital beds per 10,000 people (number) & Positive \\
\hline & & General secondary school teacher-student ratio & Positive \\
\hline & \multirow{3}{*}{$\begin{array}{l}\text { Level of economic development } \\
\text { (eco) }\end{array}$} & per capita gross regional product (yuan) & Positive \\
\hline & & Average wage of employees (yuan) & Positive \\
\hline & & Total import and export of goods (RMB) & Positive \\
\hline & \multirow[t]{3}{*}{ Social life environment (social) } & Public library book collection (million volumes) & Positive \\
\hline & & Number of museums (pcs) & Positive \\
\hline & & Number of stadiums (pcs) & Positive \\
\hline & \multirow{3}{*}{$\begin{array}{l}\text { Science and Technology } \\
\text { Innovation Environment (sci) }\end{array}$} & Number of patent applications (pieces) & Positive \\
\hline & & General higher education institutions & Positive \\
\hline & & R\&D internal funding expenditure (RMB million) & Positive \\
\hline
\end{tabular}


In the selection of methods to quantify the level of talent attractiveness of cities, considering the subjective assignment methods bring subjective correlation error, so this paper selects two objective assignment methods entropy method and principal component method to compare the results horizontally, the specific steps of the entropy method are as follows.

First, standardize the raw data and process the positive and negative indicators separately:

$$
\begin{aligned}
& \text { Positive indicator } x_{i j}=\frac{x_{i j}-\min \left(x_{i j}\right)}{\max \left(x_{i j}\right)-\min \left(x_{i j}\right)} \\
& \text { Negative indicators } x_{i j}=\frac{\max \left(x_{i j}\right)-x_{i j}}{\max \left(x_{i j}\right)-\min \left(x_{i j}\right)}
\end{aligned}
$$

Here, $x_{i j}$ is the value of the $j$ th indicator of the $i$ th city, $\min \left(x_{i j}\right)$ is the minimum value of the th indicator in the $i$ th city, and $\max \left(x_{i j}\right)$ is the maximum value of the $t$ th index in the $i$ th city.

The second step is to calculate the proportion of the ith city under the th indicator for that indicator:

$$
P_{i j}=\frac{x_{i j}}{\sum_{i=1}^{n} x_{i j}}
$$

Here, $P_{i j}$ is the weight of the $i$ th city under the th indicator for that indicator.

The third step is to calculate the entropy value of the th indicator:

$$
a_{j}=-k \sum_{i=1}^{n} P_{i j} \ln \left(P_{i j}\right)
$$

where $=1 / \ln (n)$, when $P_{i j}=0$ is given a small increment of $1 \mathrm{E}-10$

The fourth step is to calculation of information entropy redundancy:

$$
b_{j}=1-a_{j}
$$

The fifth step is to calculate the weight value of each indicator:

$$
p_{j}=\frac{b_{j}}{\sum_{j=1}^{m} b_{j}}
$$

The sixth step is to calculation of the Talent Attractiveness Index for each city:

$$
s_{i}=\sum_{j=1}^{m} p_{j} \cdot x_{i j}
$$

By calculating the above steps, the talent attractiveness index of each city in the Yangtze River Delta Urban Agglomerations was obtained and ranked, and the results are shown in Table 2.

Table 2 shows that most of the top-ranked cities are first and second-tier cities and the lower-ranked cities are mostly alternating between third and fourth-tier cities, which also show that talent attraction is closely related to the comprehensive development level of a city. In terms of spatial distribution, Shanghai ranks first, while the cities in the other three provinces in Anhui Province 
Table 2. Entropy value method Yangtze River Delta city group talent attractiveness index ranking.

\begin{tabular}{cccccc}
\hline City & Score & Ranking & City & Score & Ranking \\
\hline Shanghai & 0.896092 & 1 & Huzhou & 0.167674 & 15 \\
Hangzhou & 0.528797 & 2 & Quzhou & 0.146984 & 16 \\
Suzhou & 0.458689 & 3 & Zhenjiang & 0.134986 & 17 \\
Nanjing & 0.360547 & 4 & Taizhou & 0.127073 & 18 \\
Ningbo & 0.348529 & 5 & Yangzhou & 0.12697 & 19 \\
Wuxi & 0.299344 & 6 & Yancheng & 0.105281 & 20 \\
Hefei & 0.268662 & 7 & Xuancheng & 0.103191 & 21 \\
Jiaxing & 0.205003 & 8 & Wuhu & 0.100648 & 22 \\
Nantong & 0.201733 & 9 & Tongling & 0.085273 & 23 \\
Zhoushan & 0.199795 & 10 & Anqing & 0.084322 & 24 \\
Jinhua & 0.19878 & 11 & Maanshan & 0.081783 & 25 \\
Shaoxing & 0.188714 & 12 & Chizhou & 0.061631 & 26 \\
Taizhou & 0.186998 & 13 & Chuzhou & 0.058564 & 27 \\
Changzhou & 0.171128 & 14 & & & \\
\hline
\end{tabular}

rank behind the other two provinces.

The specific steps of the principal component method are as follows.

First using the characteristic roots, and their corresponding unit eigenvectors, find the load matrix is:

$$
A=\left(\sqrt{\lambda_{1}^{*} t_{1}^{*}}, \sqrt{\lambda_{2}^{*} t_{2}^{*}}, \cdots, \sqrt{\lambda_{m}^{*}+t_{m}^{*}}\right)=\left(t_{1}^{*}, t_{2}^{*}, \cdots, t_{m}^{*}\right)\left(\begin{array}{ccc}
\sqrt{\lambda_{1}^{*}} & & 0 \\
& \ddots & \\
0 & & \sqrt{\lambda_{m}^{*}}
\end{array}\right)
$$

where $\sqrt{\lambda_{m}^{*}}$ is the $m$ th largest eigenvalue and $t_{m}^{*}$ is the corresponding unit eigenvector.

The second step is to find the coefficients of the indicators in different linear combinations of principal components:

$$
Q_{i j}=\frac{m_{i j}}{\sqrt{\lambda_{i}^{*}}}
$$

where $m_{i j}$ is the coefficient of the loading matrix, $\lambda_{i}^{*}$ is the eigenvalue of each principal component, and the linear combination of each principal component is obtained as follows:

$$
\begin{gathered}
F_{1}=Q_{11} X_{1}+Q_{12} X_{2}+\cdots+Q_{1 n} X_{n} \\
F_{2}=Q_{21} X_{1}+Q_{22} X_{2}+\cdots+Q_{2 n} X_{n} \\
\vdots \\
F_{m}=Q_{m 1} X_{1}+Q_{m 2} X_{2}+\cdots+Q_{m n} X_{n}
\end{gathered}
$$


Thirdly, based on the coefficients in the linear combination and the variance contribution of each principal component to find the composite score model in coefficients:

$$
R_{i}^{*}=\frac{\sum_{i=1}^{n} \sum_{j=1}^{m} Q_{i j} h_{i}^{*}}{\sum_{i=1}^{n} h_{i}^{*}}
$$

where $Q_{i j}$ is the coefficient in the linear combination of the different principal components, and $h_{i}^{*}$ is the variance contribution in the different principal components.

Fourthly $R_{i}^{*}$ Normalization is applied to obtain $W_{i}^{*}$ the weights of the indicators:

$$
W_{i}^{*}=\frac{R_{i}^{*}}{\sum_{i}^{n} R_{i}^{*}}
$$

The final composite evaluation model, the larger the model, the $Z^{*}$ higher the evaluation level:

$$
Z^{*}=W_{1}^{*} X_{1}+W_{2}^{*} X_{2}+\cdots+W_{n}^{*} X_{n}
$$

The data were tested by KMO value test and Bartlett's sphericity test and the results are shown in Table 3.

The KMO value is greater than 0.8 and the Bartlett test p-value is less than 0.01 , which is suitable for principal component analysis. The talent attractiveness index of each city in the Yangtze River Delta Urban Agglomerations is derived and ranked by the principal component analysis method, and the results are shown in Table 4.

From the above table, it can be seen that the ranking order derived from the principal component method does not differ much from the results derived from the entropy method, which can also support the feasibility of the constructed index system evaluation.

\subsection{Methods}

Because it is going to explore the trend of talent attraction in different levels of cities subject to different factors, Quantile regression was first proposed by (Koenker \& Bassett, 1978), and quantile regression can be a good solution to such problems by portraying the different effects of independent variables when

Table 3. KMO and Bartlett's test.

\begin{tabular}{lcc}
\hline & KMO value & 0.809 \\
& Approximate cardinality & 428.940 \\
Bartlett sphericity test & $d f$ & 105 \\
& $p$ value & 0.000 \\
\hline
\end{tabular}


Table 4. Entropy value method Yangtze River Delta city group talent attractiveness index ranking.

\begin{tabular}{cccccc}
\hline City & Score & Ranking & City & Score & Ranking \\
\hline Shanghai & 2.69224 & 1 & Yangzhou & -0.24676 & 15 \\
Suzhou & 1.388141 & 2 & Shaoxing & -0.28398 & 16 \\
Nanjing & 0.797376 & 3 & Jinhua & -0.39884 & 17 \\
Wuxi & 0.773978 & 4 & Wuhu City & -0.45895 & 18 \\
Hangzhou & 0.377323 & 5 & Maanshan & -0.48519 & 19 \\
Zhoushan & 0.339784 & 6 & Tongling & -0.54633 & 20 \\
Ningbo & 0.279035 & 7 & Yancheng & -0.56411 & 21 \\
Jiaxing & 0.233646 & 8 & Taizhou & -0.59701 & 22 \\
Zhenjiang & 0.187045 & 9 & Quzhou & -0.61636 & 23 \\
Changzhou & 0.072594 & 10 & Chuzhou C & -0.62367 & 24 \\
Nantong & 0.016824 & 11 & Anqing & -0.62872 & 25 \\
Hefei & -0.03935 & 12 & Xuancheng & -0.67221 & 26 \\
Taizhou & -0.07641 & 13 & Chizhou & -0.72664 & 27 \\
Huzhou & -0.19345 & 14 & & & \\
\hline
\end{tabular}

the dependent variable is in different positions, and its estimator is solved by minimizing the loss function. The specific model is:

$$
\begin{gathered}
y_{t}=Q_{\tau}\left(y_{t} \mid x_{t} ; \beta\right)+u_{t} \\
\min _{\beta} \sum_{t=1}^{n} \rho_{\tau}\left[y_{t}-Q_{\tau}\left(y_{t} \mid x_{i} ; \beta\right)\right]
\end{gathered}
$$

where $Q_{\tau}\left(y_{t} \mid x_{t} ; \beta\right)$ is the $\tau$ quantile of $y_{t}$ under the condition $x_{t} ; \beta$, $\rho_{\tau}(u)=u(\tau-I(\bullet))$ is the loss function, where $I(\bullet)$ is the indicator function that takes the value of 1 when the condition within () is satisfied, otherwise is 0 . There are many ways to minimize the loss function, the common linear programming generally has difficulties, while the Bayesian approach is easier and more robust in nature, so we use the Bayesian quantile regression method, which has the following basic steps: first, assume that the quantile regression model error term obeys the asymmetric Laplace distribution, find out the likelihood function, and then obtain the sampling distribution of the regression parameters based on the Bayesian method of MCMC algorithm, and then perform the convergence test on the sampling results.

\section{Empirical Analysis}

By applying the principal component method to each of the five dimensions of the evaluation indexes separately, the composite scores of each city in different dimensions are derived, and the talent attractiveness scores obtained by the en- 
tropy method are taken as the independent variables, and the Bayesian quantile regression method based on the MCMC algorithm is used for modeling, and the results are simulated 10,000 times, with the first 4000 times excluded and the last 6000 times retained. The posterior mean values were obtained and used as estimates of the coefficients, yielding parameter estimates at five quartiles of $0.1,0.3$, $0.5,0.7$, and 0.9 , as shown in Table 5 .

Figure 1 shows the sampling trajectories of the natural ecosystem coefficients at each quantile and the posterior probability density plots.

The first row of Figure 1 shows that the sampling values of the natural ecological habitat coefficients fluctuate around a certain numerical, indicating that the Markov chains constituted by sampling the natural ecological habitat coefficients at each quantile converge, which can be used as a basis for the significant results obtained from Bayesian quantile regression, combined with Table 5, which shows that the coefficients of Bayesian quantile regression are significant at each quantile.

From the regression results and the graph of coefficient changes (Figure 2), it can be seen that the coefficient of the natural ecological environment is always greater than 0 , and the trend is slightly weakened as the quantile increases, but the overall trend is not significant, indicating that the talent attractiveness of cities with different development levels is closely related to the natural ecological environment, the better the environment, the higher the level of talent attractiveness and the marginal gain of natural ecological environment on attractiveness is weakened as the development level increases, but the overall change is not significant; the economic development level is greater than 0 in all quantile points, but the gap between high and low quantile points is larger, and the overall trend is decreasing. The economic development level is greater than 0 in all

Table 5. Bayesian quantile regression results.

\begin{tabular}{|c|c|c|c|c|c|}
\hline \multirow{2}{*}{ Variables } & \multicolumn{5}{|c|}{$\tau$} \\
\hline & 0.1 & 0.3 & 0.5 & 0.7 & 0.9 \\
\hline nature & $\begin{array}{c}0.0269^{* * *} \\
(0.0051297)\end{array}$ & $\begin{array}{c}0.0620^{\star * *} \\
(0.0111845)\end{array}$ & $\begin{array}{l}-0.0015^{\star * *} \\
(0.0120987)\end{array}$ & $\begin{array}{c}0.0389^{\star * *} \\
(0.0183634)\end{array}$ & $\begin{array}{c}0.0711^{\star * *} \\
(0.009753)\end{array}$ \\
\hline eco & $\begin{array}{l}0.0269^{\star * *} \\
(-0.0038)\end{array}$ & $\begin{array}{l}0.0452^{* * *} \\
(0.01253)\end{array}$ & $\begin{array}{c}0.0211^{* * *} \\
(0.011223)\end{array}$ & $\begin{array}{c}0.0389^{\star * *} \\
(0.012115)\end{array}$ & $\begin{array}{c}0.0726^{\star * *} \\
(0.008553)\end{array}$ \\
\hline public & $\begin{array}{c}0.0244^{* * *} \\
(0.0037287)\end{array}$ & $\begin{array}{c}0.0373^{\star * *} \\
(0.0107202)\end{array}$ & $\begin{array}{c}0.0286^{* * *} \\
(0.0079889)\end{array}$ & $\begin{array}{c}0.0429^{* * *} \\
(0.0104163)\end{array}$ & $\begin{array}{c}0.0733^{\star * *} \\
(0.0082598)\end{array}$ \\
\hline social & $\begin{array}{c}0.0226^{* * *} \\
(0.0032035)\end{array}$ & $\begin{array}{c}0.0339^{\star * *} \\
(0.0094536)\end{array}$ & $\begin{array}{c}0.0308^{\star * *} \\
(0.0060088)\end{array}$ & $\begin{array}{c}0.0493^{\star * *} \\
(0.0100623)\end{array}$ & $\begin{array}{c}0.0703^{\star * *} \\
(0.0083803)\end{array}$ \\
\hline science & $\begin{array}{c}0.0209^{* * *} \\
(0.0038014)\end{array}$ & $\begin{array}{c}0.0292^{\star * *} \\
(0.0100104)\end{array}$ & $\begin{array}{c}0.0311^{* * *} \\
(0.0057726)\end{array}$ & $\begin{array}{c}0.0549^{* * *} \\
(0.0124328)\end{array}$ & $\begin{array}{c}0.0686^{* * *} \\
(0.0107385)\end{array}$ \\
\hline
\end{tabular}

Note: ${ }^{* *},{ }^{*}$ and ${ }^{\star}$ indicate that the test was passed at the $1 \%, 5 \%$ and $10 \%$ significance levels, respectively, and the numbers in the parentheses represent the standard error. 
quartiles, but the difference between the high and low quartiles is larger, and the overall trend is downward, indicating that the economic development level is a positive gain effect on the talent attractiveness, but the improvement of the economic level in cities with low development level is more significant than that in cities with high development level; the high quartile of the public service level coefficient is different from the low quartile, and the overall trend is upward, indicating that The overall trend is upward, which means that the improvement of public service level has a positive effect on the attractiveness of talents, but the improvement of social life environment in cities with low development level has a relatively lower effect on the attractiveness of talents compared with cities with high development level. The coefficient is higher than other aspects, which indicates that the environment of science and technology development is extremely important in the talent attractiveness of cities of all development levels.
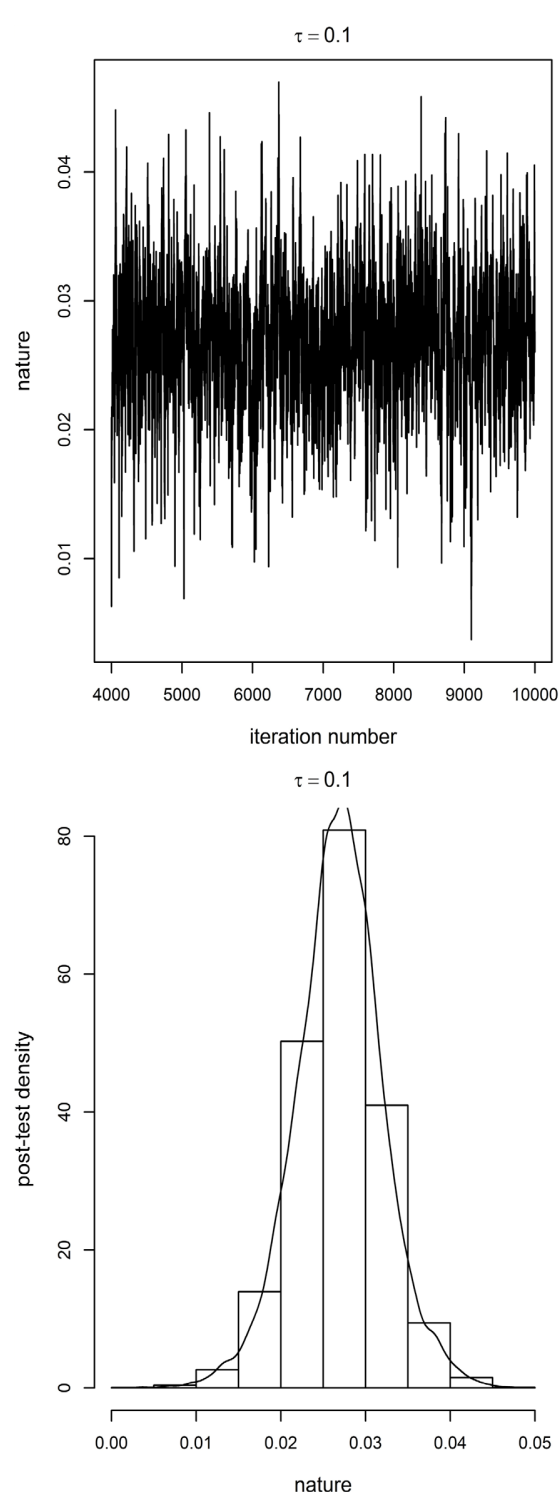
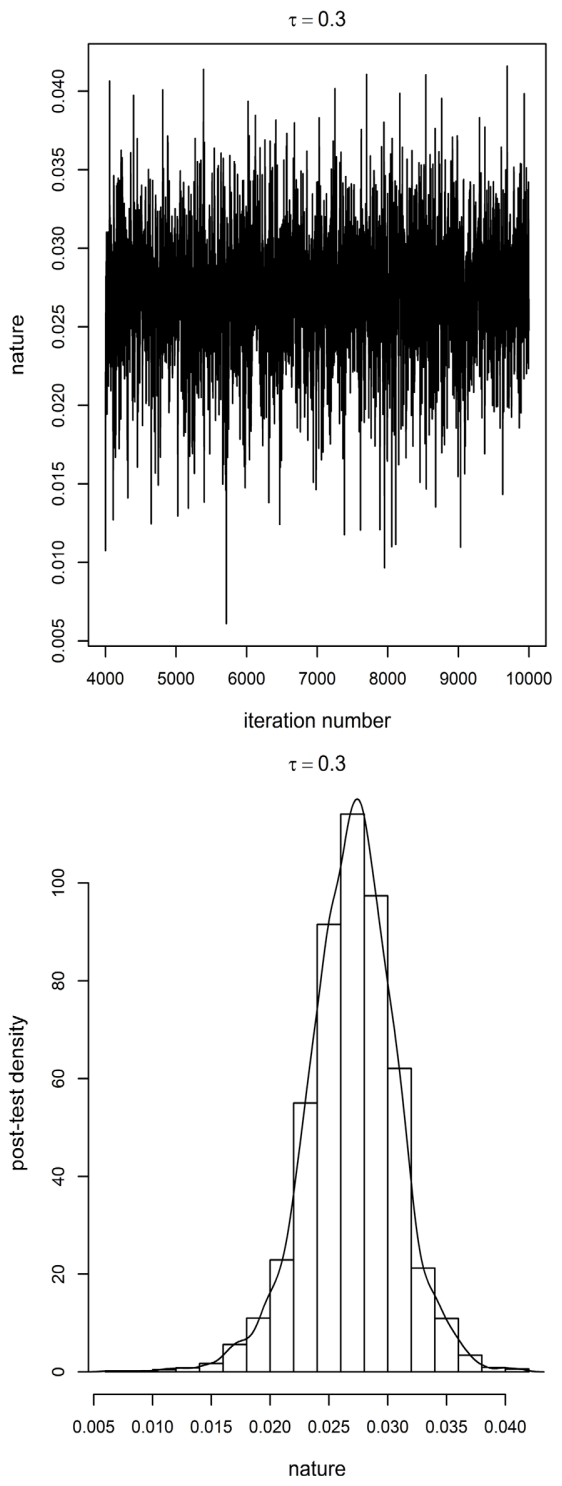
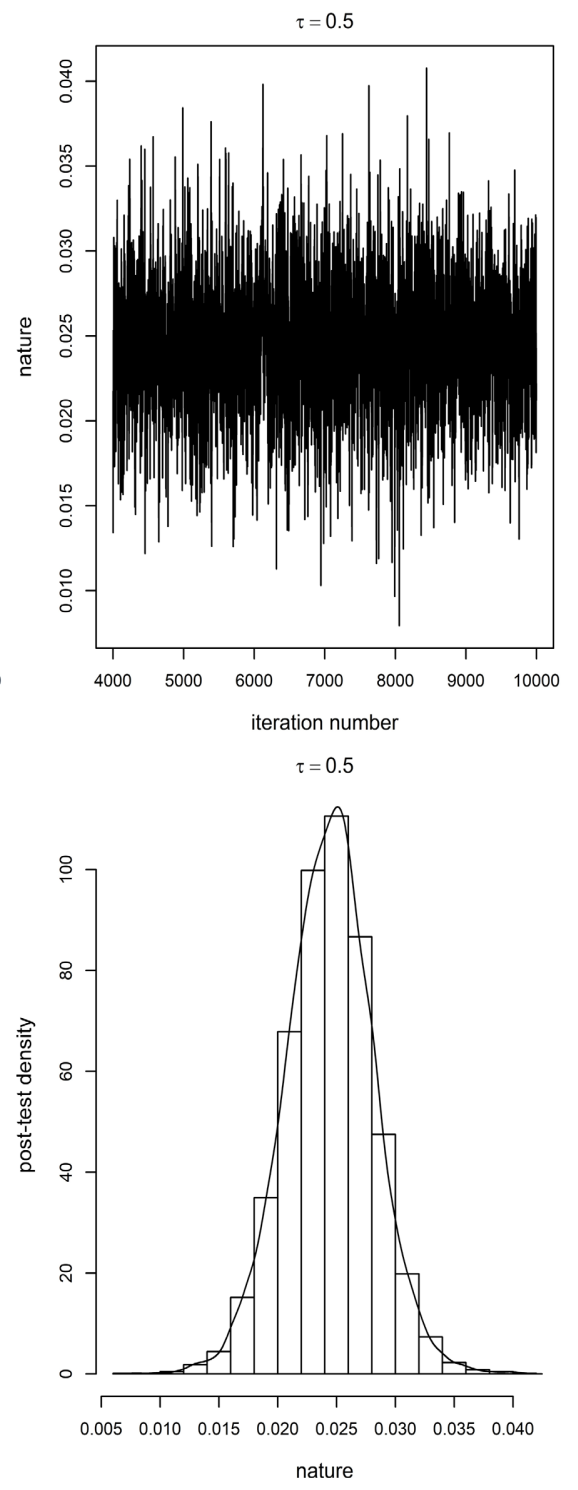

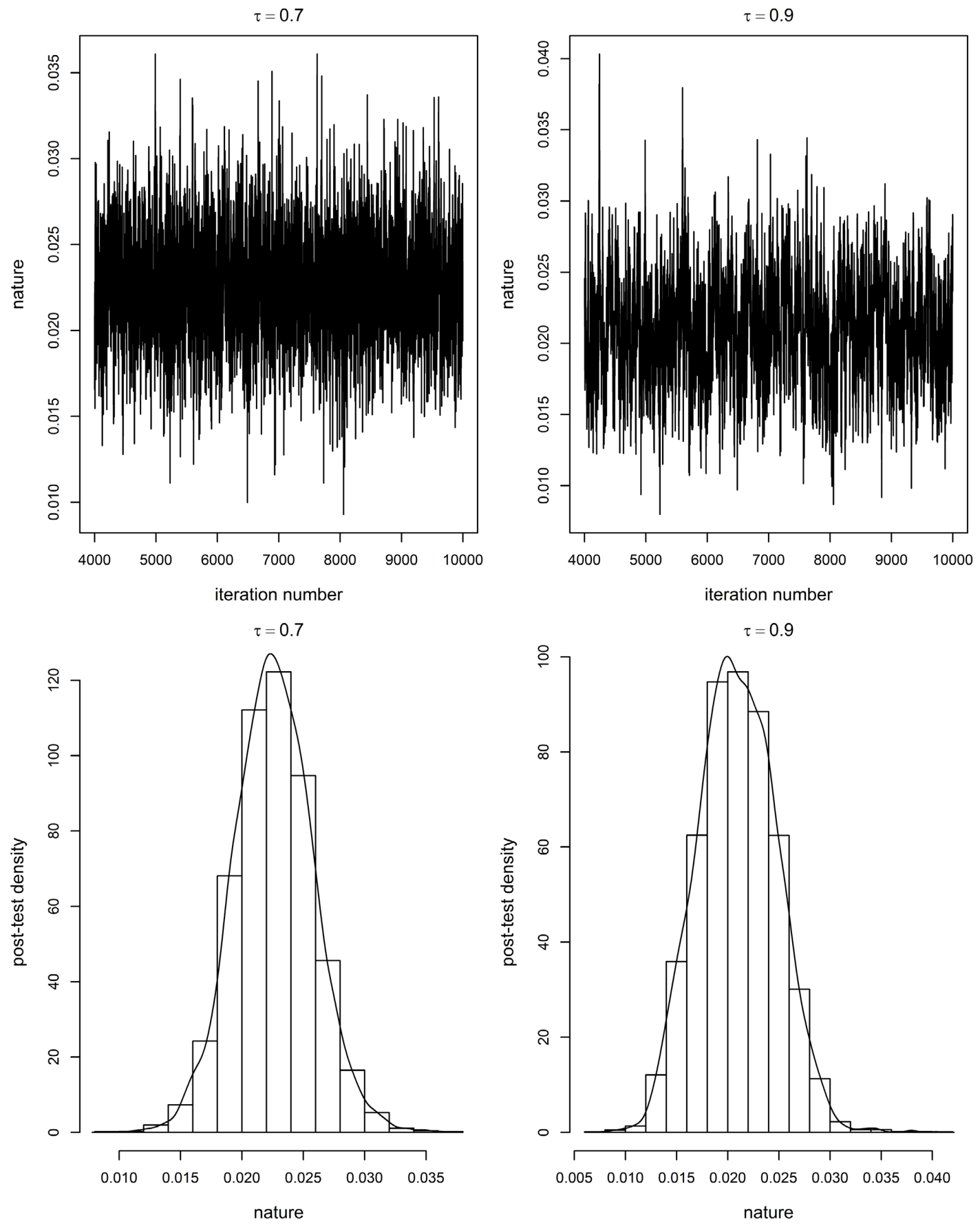

Figure 1. Trajectory diagram of the natural ecosystem coefficient sampling and posterior probability density diagram.

\section{Robustness Test}

Considering the reasonableness of index factors and analysis methods, the number of variables is expanded to test the robustness of the model, and two variables are added under each major index, "industrial wastewater discharge (million tons)" and "annual average concentration of respirable fine particulate matter $\left(\mu \mathrm{g} / \mathrm{m}^{3}\right)$ PM $2.5\left(\mu \mathrm{g} / \mathrm{m}^{3}\right)$ " are added to the natural ecological environment; 

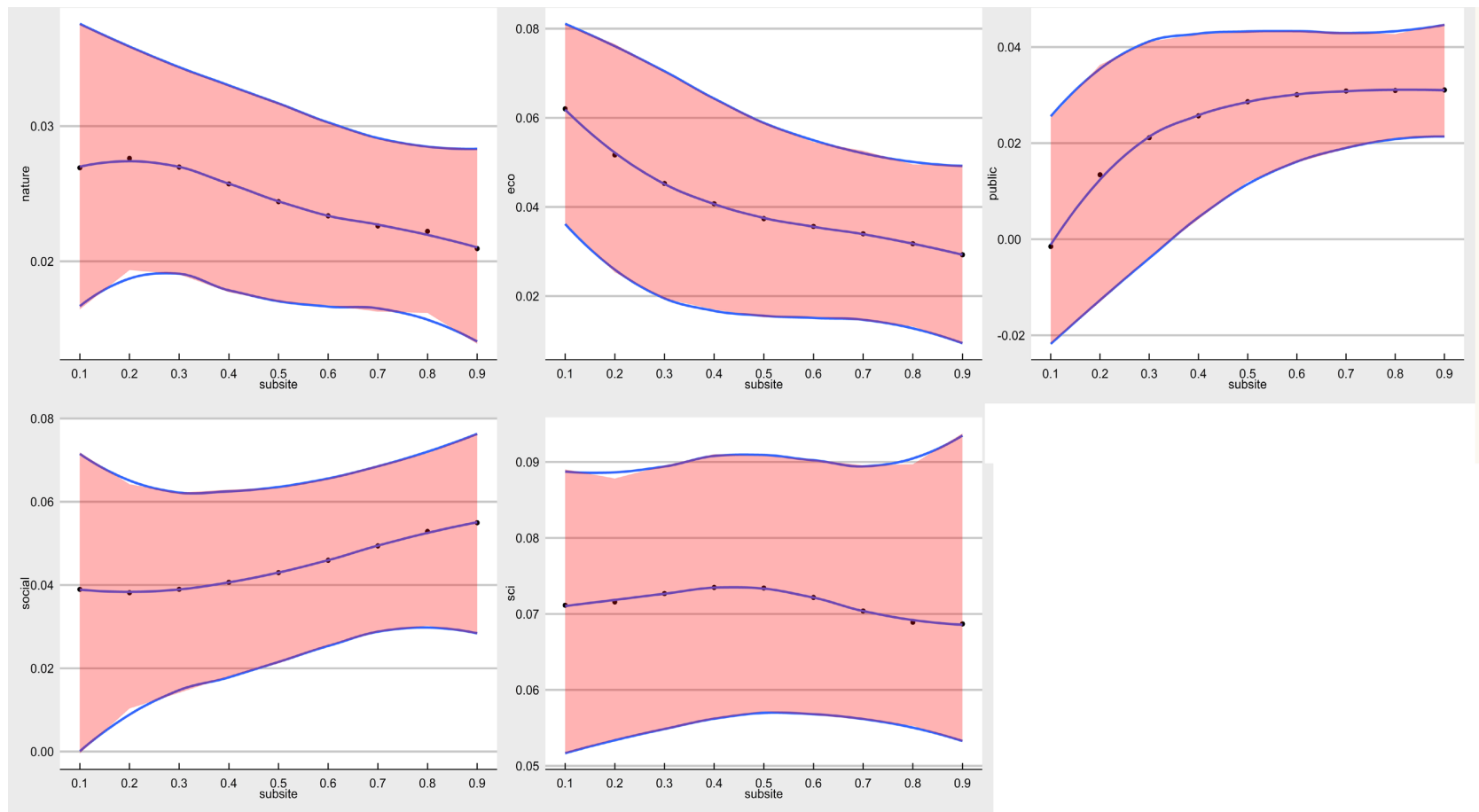

Figure 2. Bayesian quantile regression coefficient change graph.

Table 6. Robustness test results.

\begin{tabular}{|c|c|c|c|c|c|}
\hline \multirow{2}{*}{ Variables } & \multicolumn{5}{|c|}{$\tau$} \\
\hline & 0.1 & 0.3 & 0.5 & 0.7 & 0.9 \\
\hline nature & $\begin{array}{c}0.017138^{\star * *} \\
(0.002284)\end{array}$ & $\begin{array}{c}0.018163^{\star * *} \\
(0.002816)\end{array}$ & $\begin{array}{c}0.018586^{* * *} \\
(0.002926)\end{array}$ & $\begin{array}{c}0.017382^{\star * *} \\
(0.003217)\end{array}$ & $\begin{array}{c}0.016459^{* * *} \\
(0.003768)\end{array}$ \\
\hline eco & $\begin{array}{c}0.079961^{\star * *} \\
(0.005988)\end{array}$ & $\begin{array}{l}0.07961^{* * *} \\
(0.007013)\end{array}$ & $\begin{array}{c}0.079983^{\star * *} \\
(0.009166)\end{array}$ & $\begin{array}{c}0.065851^{\star * *} \\
(0.012419)\end{array}$ & $\begin{array}{c}0.055611^{\star * *} \\
(0.008922)\end{array}$ \\
\hline public & $\begin{array}{c}0.019791^{\star * *} \\
(0.002736)\end{array}$ & $\begin{array}{c}0.018305^{\star * *} \\
(0.003991)\end{array}$ & $\begin{array}{c}0.01797^{\star * *} \\
(0.00531)\end{array}$ & $\begin{array}{c}0.026371^{\star * *} \\
(0.007629)\end{array}$ & $\begin{array}{c}0.033846^{* * *} \\
(0.003715)\end{array}$ \\
\hline social & $\begin{array}{c}0.016416^{\star * *} \\
(0.007239)\end{array}$ & $\begin{array}{c}0.019109^{* * *} \\
(0.006688)\end{array}$ & $\begin{array}{c}0.018651^{\star * *} \\
(0.006679)\end{array}$ & $\begin{array}{c}0.017157^{\star * *} \\
(0.006151)\end{array}$ & $\begin{array}{c}0.014686^{\star * *} \\
(0.00691)\end{array}$ \\
\hline science & $\begin{array}{c}0.068942^{* * *} \\
(0.004322)\end{array}$ & $\begin{array}{l}0.068241^{\star *} \\
(0.005774)\end{array}$ & $\begin{array}{l}0.06874^{\star * *} \\
(0.007192)\end{array}$ & $\begin{array}{c}0.078381^{* * *} \\
(0.009513)\end{array}$ & $\begin{array}{c}0.084812^{\star * *} \\
(0.008361)\end{array}$ \\
\hline
\end{tabular}

Note: ${ }^{* *},{ }^{* *}$ and ${ }^{*}$ indicate that the test was passed at the $1 \%, 5 \%$ and $10 \%$ significance levels, respectively, and the numbers in the parentheses represent the standard error.

"number of industrial enterprises" and "year-end balance of deposits in financial institutions (million yuan)" are added to the level of economic development; "number of urban workers' basic medical insurance coverage as a percentage of household population" and "public service level" are added. The number of industrial enterprises" and "the balance of RMB deposits in financial institutions at the end of the year (RMB million)"; the level of public services increases the variables "the proportion of urban workers' basic medical insurance enrolment 
to the number of registered population" and "fixed-asset investment in urban municipal utilities construction (RMB million)"; the social living environment increases the variables "urban residents' consumption price index" and "the proportion of tertiary industry in GDP"; the variables "number of patents granted" and "R \& D personnel (people)" are added to the environment of science and technology innovation.

From the results in Table 6 above, we can see that the positive and negative coefficients of each variable at different quartiles and the trend of change are consistent with the previous paper, thus it is reasonable to analyze the influence of different factors on the attractiveness of talent at different quartiles in this paper.

\section{Conclusion}

In terms of the spatial distribution of city clusters, Shanghai has the highest level of talent attraction development, while cities located in Anhui, Zhejiang and Jiangsu provinces have the lowest level of new talent attraction compared to cities located in Anhui province.

There is little difference in the impact of technological development environment and natural ecological environment on cities of different levels. For the new attraction of talent in cities of different development levels, from different dimensions, the scientific and technological development environment has little variability in its influence on the development of different development levels, plays a positive role in the attractiveness of talent and occupies an important position in the factors influencing the attractiveness of talent in cities of different levels, and the natural ecological environment plays the same positive role and little difference in its influence on the attractiveness of talent in cities of different levels, but the level of influence is lower than that of Science and technology development environment.

The social living environment, public service level and economic development level have different degrees of influence on the talent attractiveness of cities of different levels. The social living environment and public service level gradually increase the degree of influence on talent attractiveness as the city level increases, while the economic development level has a greater influence on cities with lower city level.

From the results, when talents choose to go to cities with lower development level, the ratio of considering natural environment and economic development is higher than that of going to cities with better development level, while when they go to cities with higher development level, they will pay more attention to the level of public services and social entertainment and cultural environment, so cities with low development level give relatively higher priority to the construction of economy and environment when making policies, while cities with high-level development give the construction priority of services and social and recreational life is relatively higher. 


\section{Foundation Project}

National Natural Science Foundation of China (61763008, 71762008, 62166015);

Guangxi Science and Technology Planning Project (2018GXNSFAA294131, 2018GXNSFAA050005).

\section{Conflicts of Interest}

The authors declare no conflicts of interest regarding the publication of this paper.

\section{References}

Audretsch, D., \& Feldman, M. (2004). R\&D Spillovers and the Geography of Innovation and Production. American Economic Review, 86, 630-640.

Gao, Z. P. (2012). Research on Talent Attractiveness of Shanghai Based on Hierarchical Analysis. East China Economic Management, 26, 5-9.

Koenker, R., \& Bassett, G. (1978). Regression Quantiles. Econometrica, 46, 33-50. https://doi.org/10.2307/1913643

Li, N. W., \& Li, F. Z. (2011). Research on the Attractiveness of Talent Based on Talent Gathering Carriers-Take the Northwest Liaoning Region as an Example. Population \& Economics, 6, 41-48.

Lin, J. X., He, J. L., \& Huang, X. J. (2020). A Study on City Preferences of Research Talent Mobility from the Perspective of Urban Comfort. Areal Research and Development, 39, $59-64,88$.

Lin, X. Y., Shi, Z. H., Luo, S., Wu, D., \& Shi, M. T. (2015). Analysis of the Impact of High-Speed Railroad on the Attractiveness of Urban Talents. Journal of Beijing Jiaotong University (Social Science Edition), 14, 7-16.

Liu, J., Zhao, P., \& Su, F. G. (2015). A Study on the Factors Influencing the Attractiveness of Financial Talents in Shenzhen Based on Rooting Theory. Journal of Shenzhen University (Humanities \& Social Sciences), 32, 130-135.

Lucas, R. E., \& Rossi-Hansberg, E. (2002). On the Internal Structure of Cities. Econometriva, 70, 1445-1476. https://doi.org/10.1111/1468-0262.00338

March, J. G., \& Simon, H. (1958). The International Mobility of Technical Talent. LTNU Wider Press, 23, 12-22.

Mobley, W. H. (1982). Employee Turnover: Causes, Consequences, and Control. The Lancet, 11, 542-546.

Palivos, T., \& Wang, P. (2008). Spatial Agglomeration and Endogenous Growth. Regional Science Urban Economics, 26, 25-64.

Porter, M. E. (1998). Clusters and the New Economics of Competition. Harvard Business Review, 76, 77-90.

Qian, H. F. (2010). Talent, Creativity and Regional Economic Performance: The Case of China. The Annals of Regional Science, 45, 133-156.

https://doi.org/10.1007/s00168-008-0282-3

Song, H., \& Chen, H. (2006). Quantitative Evaluation and Comparison of Regional Talent Attractiveness. Human Resources Development of China, 3, 26-28.

Weng, Q., \& McElroy, J. C. (2010). HR Environment and Regional Attraction: An Empirical Study of Industrial Clusters in China. Australian Journal of Management, 35, 
245-263. https://doi.org/10.1177/0312896210384679

Xu, B., Song, W., Gao, X., \& Zhang, Y. (2019). Research on the Science and Technology Policy Coordination of China's Yangtze River Delta. American Journal of Industrial and Business Management, 9, 875-885. https://doi.org/10.4236/ajibm.2019.94059

Ye, X. Q., \& Chen, W. (2019). Research on the Comprehensive Attractiveness of China's Cities to Scientific and Technological Innovation Talents-Construction and Empirical Evidence of Evaluation Indexsystem Based on Comfort Object Theory. Studies in Science of Science, 37, 1375-1384.

Zeng, S. K., \& Li, X. H. (2019). An Empirical Study on the Factors Influencing Talent Attractiveness in the Context of Rural Revitalization-Based on Survey Data in the Western Part of Chongqing. Journal of Chinese Agricultural Mechanization, 40, 214-220.

Zhang, R. H. (2012). Research on the Evaluation of Environmental Talent Attractiveness of Industrial Clusters in Henan Province. Science and Technology Management Research, 32, 180-184.

Zhang, W., Jing, W. M., \& Wang, Y. J. (2017). What Determines the Attractiveness of First-Tier Cities to Talents?-A Test Analysis of the Influencing Factors Based on Random Forest Method. Science and Technology Management Research, 37, 99-108. 